\title{
Formulation and Acceptability of Sports Drinks using Fruit Juices and Tender Coconut Water
}

\author{
Lalitha Ramaswamy* and Zeba Fathima. F**
}

\begin{abstract}
The aim of the study is to formulate sports drinks using fruit juices and tender coconut water and to test their organoleptic acceptability. Sports drinks were developed using sweet lime juice (F1), lime juice (F2), pineapple juice (F3) and tender coconut water (F4) blended with honey, salt and water. The prepared sports drinks were calculated for their nutrient content and organoleptically evaluated using a 5 point hedonic scale. The energy content of $\mathrm{F} 4$ was the highest $(68.3 \mathrm{Kcal} / 100 \mathrm{ml})$, followed by F1 $(65.35 \mathrm{Kcal} / 100 \mathrm{ml})$ and $\mathrm{F} 3 \mathrm{had}$ the lowest value of $54.9 \mathrm{Kcal} / 100 \mathrm{ml}$. The iron content of F3 was the highest $(1.2 \mathrm{mg} \%)$. The amount of sodium and potassium of F1 was high (237.1 and $245.78 \mathrm{mg} \%)$ and almost equal in quantity. The sodium content of F3 was highest (301.05 mg \%) followed by F4 $(289.6 \mathrm{mg} \%)$ and F2 (473.8 $\mathrm{mg} \%)$. The potassium content of F3 was the least (47.38 $\mathrm{mg} \%$ ), while that of F2 and F4 was $140.19 \mathrm{mg} \%$ and $128.69 \mathrm{mg} \%$ respectively. The mean scores obtained for overall acceptability was $3.5 \pm 0.7,3.1 \pm 0.7,4.2 \pm 0.6$ and $4.6 \pm 0.5$ for F1, F2, F3, F4 respectively. F3 and F4 obtained a mean score of more than 4.0 for taste and overall acceptability. Results of ANOVA indicate no significant difference for colour, appearance and flavour $(\mathrm{p} \geq 0.05)$ between the four variants whereas it was significant for texture, taste and overall acceptability $(\mathrm{p} \leq 0.05)$. The formulated sports drinks contribute to the nutrient requirement of the athletes. On comparing the costs of all the formulated sports drinks, F4 (sports drink made from tender coconut water) was found to be more cost effective and had less food wastage. It may be concluded that sports drink prepared with tender coconut water (F4) being highly acceptable and cost effective can be recommended for athletes for optimal performance.
\end{abstract}

Key words: Sports drinks, Tender coconut water, Organoleptic evaluation, Hydration

\section{Introduction}

Consumption of a sports drink will provide a large amount of water in addition to other components which could otherwise be obtained from food. The majority of mainstream sports drinks have a carbohydrate content close to $6 \%$ weight/ volume and contain small amounts of electrolytes, the main one being sodium (Shirreffs, 2009). Sport drinks are ubiquitous within the recreational and competitive fitness and sporting world. Most are manufactured and artificially flavoured carbohydrateelectrolyte beverages (Kalman et al., 2012).

\footnotetext{
*Dr. Lalitha Ramaswamy, Associate Professor and Head, Department of Nutrition and Dietetics, PSG College of Arts and Science, Avinashi Road, Civil Aerodrome, Coimbatore-641014,Tamil Nadu, India. Email: lalitharam58@gmail.com

**Zeba Fathima. F, Student, Department of Nutrition and Dietetics, PSG college of Arts and Science, Avinashi Road, Civil Aerodrome, Coimbatore-641014,Tamil Nadu, India.

Email: zebafathima_1994@yahoo.com
} 
Intake of adequate amount of fluids is necessary for optimal performance of athletes. Adequate hydration ensures the body's ability to transport nutrients and oxygen to the muscles and regulates body temperature during performance. The purpose of fluid consumption during exercise is primarily to maintain hydration and thermoregulation, thereby benefiting performance. Evidence is emerging on increased risk of oxidative stress with dehydration. Fluid consumption prior to exercise is recommended to ensure that the athlete is well-hydrated prior to commencing exercise. In addition, carefully planned hyper hydration (fluid overloading) prior to an event may reset fluid balance and increase fluid retention, and consequently improve heat tolerance. However, fluid overloading may increase the risk of hypernatremia and impact negatively on performance due to feelings of fullness and the need to urinate (Beck et al., 2015).

Hydration requirements are closely linked to sweat loss, which is highly variable $(0.5-2.0$ L/hour) and dependent on type and duration of exercise, ambient temperature, and athletes' individual characteristics. Excessive sweating can lead to loss of body weight, which can impair the athletes' ability to perform. Sodium losses linked to high temperature can be substantial, and in events of long duration or in hot temperatures, sodium must be replaced along with fluid to reduce risk of hypernatremia (Sowka et al., 2007).

Recently, attention has been given to coconut water, a natural alternative to sport drinks, with initial evidence indicating efficacy with regard to maintaining hydration. Coconut is a very versatile and indispensable food item for most people under the tropical belt. A mediumsize nut carrying $400 \mathrm{~g}$ edible meat and some 30 $150 \mathrm{ml}$ of water may provide almost all the daily-required essential minerals, vitamins, and energy of an average-sized individual (Omale et al., 2016).

Coconut water is the juice of the endosperm found within the cavity of the coconut, which begins to form around two months after the natural opening of the inflorescence. According to research, coconut water accounts for $25 \%$ of the weight of the fruit, and its basic composition is $95.5 \%$ water, $4 \%$ carbohydrates, $0.1 \%$ fat, $0.02 \%$ calcium, $0.01 \%$ phosphorous, $0.5 \%$ iron, in addition to amino acids, vitamin C, B complex vitamins and mineral salts (Arago et al., 2000). Coconut water is naturally occurring, very rich in potassium, contains sodium, chloride, and carbohydrate, and is viewed as the hydrating beverage of choice in certain parts of the world (Feldman et al., 2012).

In some countries coconut water is used as a solution for oral hydration, as part of the daily diet and as a protein supplement when nutritional deficits are intense. During the Second World War, coconut water was even used instead of saline solution during emergency surgeries. Coconut water can be used for electrolyte replacement in a wide range of situations (Ferraz et al., 2003).

The objective of the study is to formulate sports drinks using natural ingredients rich in vitamins and minerals for athletes and finding out their organoleptic acceptability and nutrient content.

\section{Materials and Methods}

\section{Selection of Ingredients}

It is necessary to drink fluids during exercise to prevent a drop in performance due to dehydration and also after the exercise to rehydrate. A pilot study was conducted to select the ingredients and arrive at the proportion for the preparation of sports drink. The juices of sweet lime, lime and pineapple, and tender coconut water were selected. Each of the fruit juices was blended with honey, salt and sugar in formulating the drink. Four different sports drinks made up of sweet lime (F1), lime (F2), pineapple (F3) and tender coconut water (F4) were prepared.

The formulated drink was well accepted in all the criteria by the evaluators except for the fact that the honey content in the tender coconut water drink was insufficient and the sweet lime drink had a bitter taste. The salt content in the pineapple drink was also insufficient. After analysing the comments of the panel members, 
Figure 1. Preparation of Sports Drinks
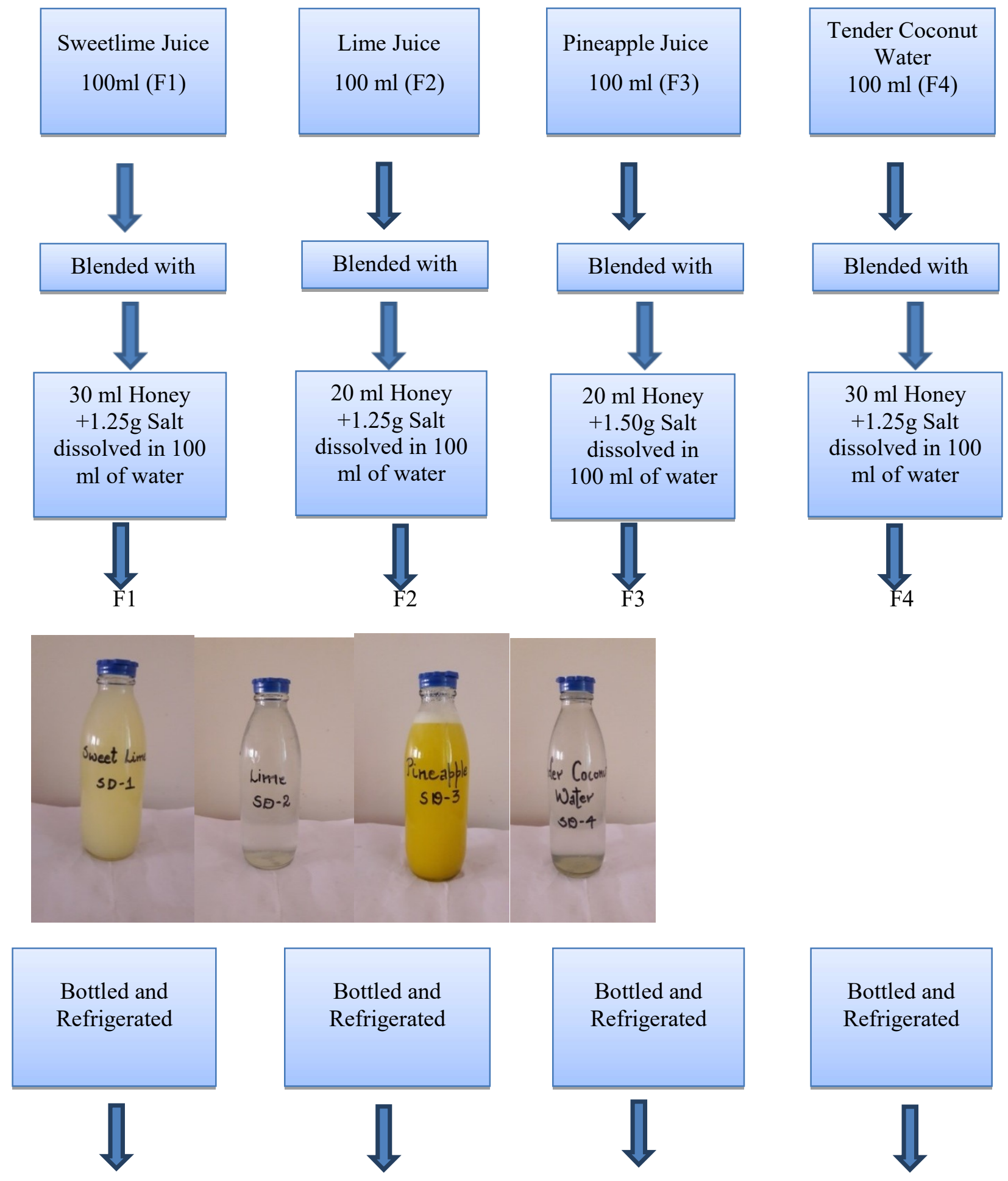

Organoleptic Evaluation 
minor modifications in the formula of F1, F2, F3 and F4 were made. Extra amount of honey was added to the drink made of sweet lime juice and tender coconut water, while salt content was increased in the drink made of pineapple juice (Fig 1).

\section{Preparation of Sports drinks}

Fruit juices from lime and sweet lime were extracted by gently squeezing them. Pineapple juice was extracted by using a blender. Tender coconut water was directly taken from the coconut. The above ingredients were measured and kept separately. Equal amount of water measured was warmed to dissolve the salt and honey and allowed to cool to room temperature. Each of the fruit extracts and tender coconut water were mixed together with honey and salt mixture and filled in separate bottles and refrigerated. No synthetic additive was added to it. The preparation of drinks is shown in Figure 1.

\section{Sensory Evaluation}

The human responses (sight, smell, taste, touch and hearing) are measured in the sensory evaluation of foods and drinks to assess appearance, touch, odour, texture, temperature and taste. The prepared sports drinks were evaluated for their sensory characteristics such as colour, appearance, texture, flavour, taste and overall acceptability by a 10 member semitrained panel at $11 \mathrm{am} / 3 \mathrm{pm}$ using a 9 point hedonic scale. The mean of the scores was calculated and the scores were statistically analysed using ANOVA.

\section{Nutrient Composition}

The nutrient content of the prepared sports drink was calculated using "Nutritive Value of Indian Foods" (National Institute of Nutrition, ICMR), 2011.

\section{Results and Discussion}

\section{Nutritional Composition of Sports Drink}

The energy content (Table I) of F4 was the highest $(68.3 \mathrm{Kcal} / 100 \mathrm{ml})$, followed by $\mathrm{F} 1$ $(65.35 \mathrm{Kcal} / 100 \mathrm{ml})$ and $\mathrm{F} 3$ which had the lowest value of $54.9 \mathrm{Kcal} / 100 \mathrm{ml}$ the iron content of $\mathrm{F} 3$ was the highest $(1.2 \mathrm{mg} \%)$. The amount of sodium and potassium in F1 was high (237.1 and $245.78 \mathrm{mg} \%$ ) and almost equal in quantity. The sodium content of $\mathrm{F} 3$ was highest (301.05 $\mathrm{mg} \%$ ) followed by F4 (289.6 $\mathrm{mg} \%)$ and F2 (473.8 mg $\%$ ). However the potassium content of F3 was least (47.38 $\mathrm{mg} \%$ ). While that of F2 and F4 was $140.19 \mathrm{mg} \%$ and $128.69 \mathrm{mg} \%$ respectively. Tender coconut water is also rich in other biological constituents like amino acids, enzymes, minerals, and fatty acids which accounts for this higher osmolality. Nonetheless, unlike WHO-ORS, its water is very low in sodium and chlorides, but rich in sugars and amino acids (Ganguly et al., 2015). This wellbalanced fluid composition, along with muchneeded calories, would be an ideal drink instead of any other kind of soft drink beverages available in the markets to correct dehydration conditions (Sunidhi et al., 2017). Addition of honey to the drink not only added to the flavour but also to the nutrient content as honey is rich in fructose, glucose, proteins, moisture, ascorbic acid, niacin, potassium, calcium, sodium, phosphorous and organic acids (Ahmed, 2016).

\section{Results of Sensory Evaluation}

The sensory attributes and the mean organoleptic scores of the sports drinks are graphically indicated in Figure 2. The mean scores obtained for overall acceptability was $3.5 \pm 0.7,3.1 \pm 0.7,4.2 \pm 0.6$ and $4.6 \pm 0.5$ for sweet lime, lime, pineapple and tender coconut water drink respectively. F3 and F4 obtained a mean score of more than 4.0 for taste and overall acceptability. Results of ANOVA indicate no significant difference in colour, appearance and flavour $(p \geq 0.05)$ between the four samples whereas it was significant for texture, taste and overall acceptability $(p \leq 0.05)$. The formulated sports drinks contribute to the nutrient requirement of the athletes.

\section{Cost}

On comparing the selling costs of all the formulated sports drinks (Table II), F4 (sports drink made from tender coconut water) was found to be more cost effective and also had less food wastage. This could be because coconut is widely grown in Coimbatore-Pollachi belt and is 
Table I. Nutrient Content of the Formulated Sports Drinks

\begin{tabular}{|l|l|l|l|l|}
\hline & \multicolumn{4}{|c|}{ SPORTS DRINKS } \\
\hline NUTRIENTS & F1 & F2 & F3 & F4 \\
\hline Energy (Kcal \%) & $65.35^{*}$ & $61.4^{*}$ & $54.9^{*}$ & $68.35^{*}$ \\
\hline Carotene (mcg \%) & $0.0^{*}$ & $7.5^{*}$ & $9.0^{*}$ & $0.0^{*}$ \\
\hline Vit c (mg \%) & $22.5^{*}$ & $31.5^{*}$ & $19.5^{*}$ & $0.0^{*}$ \\
\hline Calcium (mg \%) & $16.25^{*}$ & $46.0^{*}$ & $11.0^{*}$ & $6.25^{*}$ \\
\hline Iron (mg \%) & $0.46^{*}$ & $0.22^{*}$ & $1.28^{*}$ & $0.568^{*}$ \\
\hline Sodium (mg \%) & $237.1^{*}$ & $236.9^{*}$ & $301.05^{*}$ & $289.6^{*}$ \\
\hline Potassium (mg \%) & $245.78^{*}$ & $140.19^{*}$ & $23.69^{*}$ & $128.69^{* *}$ \\
\hline
\end{tabular}

* Nutritive Value of Indian Foods (2011)

**USDA National Nutrient Database

Figure 2. Mean Scores of Organoleptic Evaluation of Sports Drinks

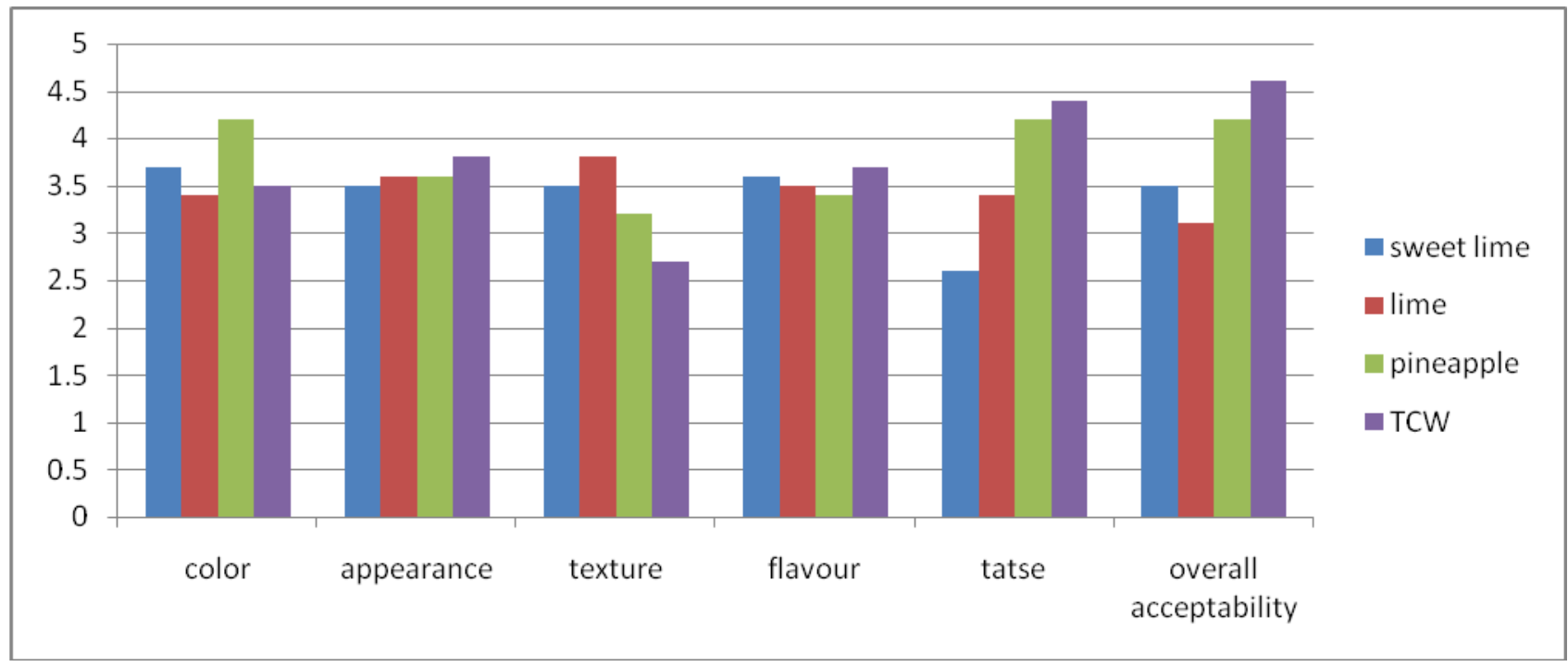

Table II. Selling cost of the Formulated Sports Drinks

\begin{tabular}{|c|c|c|}
\hline S. No & Name of the Sports drink & Cost (Indian rupee) \\
\hline 1 & F1 $(200 \mathrm{ml})$ & 20 \\
\hline 2 & F2 $(200 \mathrm{ml})$ & 32 \\
\hline 3 & F3 $(200 \mathrm{ml})$ & 32 \\
\hline 4 & F4 $(200 \mathrm{ml})$ & 16 \\
\hline
\end{tabular}


easily available. Since the study was carried out in this geographic belt, it was possible to develop F4 at this cost.

The sports drinks thus developed will help in making up the fluid and electrolyte lost through exertion. These drinks are light and refreshing as they are prepared from natural food sources. The therapeutic and nutritive value of the developed sports drinks can be highlighted and recommended as rejuvenating drinks.

Consumers' demands have undergone a change with the realisation of foods from natural sources contributing to good health. The increase in demand for such drinks by the people especially athletes can also be explained by the increased cost of commercially available drinks. Since, the desire for such natural drinks has increased, all the developed drinks are suitable, especially F4 which is prepared with tender coconut water.

\section{Conclusion}

It is clear from the results, that F3 and F4are almost equally acceptable. However the cost of F3 was much higher than the one prepared with F4. Also, tender coconut is available right throughout the year in contrast to pineapple which is a seasonal fruit. Therefore, it can be concluded that F4 (sports drink prepared with tender coconut water) is ideal for athletes.

\section{Recommendations}

- The formulated sports drink can be pasteurised before bottling to study the shelf life in terms of microbial growth, organoleptic changes and nutrient content.

- $\quad$ Sports drinks can be formulated using water from mature coconut which may bring down the cost.

- Formulations of the sports drinks can be made by replacing honey with coconut sap syrup or coconut sap sugar as sweetener.

\section{References}

Ahmed, Mahmood; Shafiq, Muhammad Imtiaz; Khaleeq, Anum; Huma, Rahila; Qadir, Muhammad Abdul; Khalid Ayesha; Ali, Amir and Samad, Abdul, 2016.
"Physiochemical, Biochemical, Minerals Content Analysis, and Antioxidant Potential of National and International Honeys in Pakistan”Vol. 2016, p: 2.

Aragão, WM. Aimportância do coqueiro-anão verde. Links: http://www21.sede. embrapa.br/noticias/ artigos/2000/ artigo. 2004-12-07. 2461636373/mostra artigo. Accessed on: 9/2/2017

Beck, L Kathryn; Thomson, S Jasmine; Swift, J Richard; Von Hurst, R Rameela, 2015. "Role of nutrition in performance enhancement and post exercise recovery", Vol (6), pp-259-267.

Ferraz, LGB, Fonseca, MAC, Freitas, EV. IPA responde. Coqueiro. www.ipa.br/RESP/ resp42.htm. Accessed on: 9/2/2017.

Ganguly, Subha; Roy, Satpura, 2015. "Medicinal Plants and Herbs: A Review", Vol 6(3), pp: 4288-4290.

Gopalan, C; Sastri, B.V. Rama; Balasubramanian, S.C, 2011. "Nutritive Value of Indian Foods".

Kalman, Douglas S; Feldman, Samantha., Krieger, Diane R; and Bloomer, J Richard, 2012. "Comparison of coconut water and a carbohydrate-electrolyte sport drink on measures of hydration and physical performance in exercise-trained men", J Int Soc Sports Nutr; 9: 1.

Mishra, Sunidhi; Agrahari, Kiran; Shah, K Dharti, 2017. "Intervention and Effect of Coconut Water On Dengue Patients "Vol (4), pp: 2394-4404.

Omale, JA; Omale, A; and Olupinyo, O, 2016. "Proximate analysis, Phytochemical Screening and supported by Physicochemical properties of cocos nucifera oil extract", Vol (1), pp: 363-366.

Sawka MN, Burke LM, Eichner ER, Maughan RJ, Montain SJ, Stachenfeld NS, American College of Sports Medicine American College of Sports Medicine position stand. Exercise and fluid 
Cord 2017, 33 (1)

replacement. Med Sci Sports Exerc. 2007; 39(2): 377-390.

Shirreffs, S. M, 2009. "Hydration in sport and exercise: water, sports drinks and other drinks". Vol (34), Issue 4, pp: 374-379. 